\title{
A CONTROLADORIA COMO FERRAMENTA ORGANIZACIONAL NAS MICRO E PEQUENAS EMPRESAS
}

\section{ARTIGO ORIGINAL}

BRITO, Klissia Rodrigues ${ }^{1}$, SERRA, Meg Rocha da Cunha ${ }^{2}$, LOPES, Nelânia Ferreira $^{3}$, ROBERTO, José Carlos Alves ${ }^{4}$

BRITO, Klissia Rodrigues. Et al. A controladoria como ferramenta organizacional nas micro e pequenas empresas. Revista Científica Multidisciplinar Núcleo do Conhecimento. Ano. 06, Ed. 11, Vol. 02, pp. 103-126. Novembro 2021. ISSN: 24480959, Link de acesso:

https://www.nucleodoconhecimento.com.br/administracao/ferramenta-organizacional, DOI: 10.32749/nucleodoconhecimento.com.br/administracao/ferramentaorganizacional

\section{RESUMO}

O presente artigo teve como finalidade a apuração do processo da aplicabilidade da controladoria como opção para as micro e pequenas empresas. Em síntese, pela decorrência do alto índice de fechamento de microempresas, levando em consideração as dificuldades da gestão organizacional, apresenta-se a formação estrutural e organizacional da controladoria como estratégia, afirmando, deste modo, sua importância enquanto objeto que colabora com as organizações empresariais. Nota-se que uma das causas da falência das micro e pequenas empresas é a falta de conhecimento dos gestores acerca da estrutura organizacional, cujos empresários e administradores, geralmente, atuam com o mesmo papel. Destaca-se

\footnotetext{
${ }^{1}$ Graduanda do curso de Ciências Contábeis.

${ }^{2}$ Orientadora. Mestra em Engenharia de Processos Industriais pela UFPA, especialista em Controladoria e Auditoria Contábil pelo Ciesa (2020), Graduada em Ciências Contábeis pelo Centro Universitário do Norte (2010). Graduada em Ciências Econômicas pelo Centro Universitário do Norte (2006).

${ }^{3}$ Orientadora. Especialista em Auditoria Contábil, Financeira e Tributaria e Graduada em Ciências Contábeis.

${ }^{4}$ Orientador. Mestre em Engenharia de produção. Especialista Logística empresarial. Graduado em Administração com Ênfase em Marketing.
}

$\mathrm{RC}: 100632$

Link de acesso: 
a seguinte pergunta: Quais as ferramentas que a controladoria pode proporcionar para gestão das micro e pequenas empresas? O objetivo geral do artigo foi mostrar as ferramentas juntamente com aplicabilidade da controladoria nas micro e pequenas empresas, visando a melhoria nos processos para tomada de decisão, tendo como consequência a permanência destes no mercado. Foi desenvolvido a partir de uma pesquisa bibliográfica realizada por meio de artigos, livros e documentos já publicados. A pesquisa parte do método quali-quantitativo, utilizandose de materiais publicados e estatísticas envolvendo o tema principal, tendo este caráter relevante, cujo intuito é gerar conhecimento para propósito aplicável. Quanto aos meios, o procedimento usado foi a pesquisa bibliográfica, contando-se com documentos publicados. Por fim, ao observar-se, ao longo do estudo, os ambientes interno e externo organizacional pelas lentes da controladoria, conclui-se que ela pode proporcionar ferramentas aplicáveis e adequadas à gestão das microempresas.

Palavras-chave: Controladoria, Gestão Organizacional, Ferramentas, Microempresa.

\section{INTRODUÇÃO}

O objetivo deste artigo é demonstrar as ferramentas e aplicabilidade da controladoria nas micro e pequenas empresas, visando à melhoria nos processos para tomadas de decisões mais assertivas, com o objetivo de manter-se no mercado com longevidade. A importância das pequenas empresas para o Brasil resulta em tornálas prioridade para os poderes públicos, visto que somente por meio do fortalecimento do empreendedorismo a economia do país melhora (DOMINGOS, 2021) Nas grandes empresas, geralmente, conta-se com profissionais específicos ligados, respectivamente, a seus cargos, aptos a responder de acordo com seu departamento. Já nas microempresas, o empresário, geralmente, corresponde ao gestor, tornando-se o tomador de decisões e administrador de todo negócio, sendo que, infelizmente, por falta de conhecimento, acaba deixando a empresa em más condições, levando até ao seu fechamento. 
Diante do exposto, levanta-se a seguinte questão: Quais as ferramentas que a controladoria pode proporcionar para gestão das micro e pequenas empresas? Segundo Eleutério (2016), quando se fala de controladoria, é essencial que haja um local onde exista a finalidade do domínio do conjunto de informação e que proporcione medidas apropriadas ao procedimento da tomada de decisão. Entretanto, isto não significa, necessariamente, a necessidade de se abrir um departamento, com vários funcionários especialistas, repletos de técnicas e processos. Na realidade, todos os conceitos servem como modelo para serem aplicados de acordo com as particularidades de cada empresa.

A metodologia escolhida, quanto à natureza, é de caráter quanti-qualitativo, pois utiliza-se de estudos sociais que dispõem sobre dados. Quanto aos fins, foi utilizado o método aplicável, pois tem-se o objetivo de acrescentar como opção às empresas e aos empreendedores a possibilidade de utilização da controladoria. Quanto aos meios, utilizou-se do bibliográfico, pois todo o suporte de informações desta pesquisa será apoiado nos livros e artigos divulgados a respeito do assunto.

Desenvolver-se-á a explanação do conteúdo, primeiramente, com a apresentação da controladoria, desde sua origem até suas funções, incluindo o conceito de micro empreendedorismo e os problemas enfrentados pelos gestores dessas empresas, consequentemente, será discutido sobre como a controladoria e suas ferramentas podem ser úteis à permanência e desenvolvimento das micro e pequenas empresas no mercado.

\section{FUNDAMENTAÇÃO TEÓRICA}

A fundamentação teórica atua a partir de um compilado que reúne as informações relevantes sobre um tema e tem como alvo a indicação para outros estudos. Iniciase uma investigação com base em uma tese já existente. Nesta parte do trabalho, demonstrar-se-á de forma mais detalhada a disseminação do conteúdo, juntamente com suas propriedades.

RC: 100632

Link de acesso:

https://www.nucleodoconhecimento.com.br/administracao/ferramenta-organizacional 


\subsection{CONTROLADORIA}

A controladoria pode ser comparada a uma caixa de ferramentas, com vários compartimentos e, dentre esses compartimentos, existem diversas chaves de fenda, jogo de chaves, trenas etc. Logo, Borinelli (2006 apud GOMES, 2014) demonstra que a controladoria é formada por um agrupamento de informação que tem como auxílio às organizações, tocantes à técnica de comando organizacional. Contudo, mesmo que se entenda que a contabilidade é apenas mais um tipo de ferramenta na controladoria, ela é, na verdade, a base.

Martins e Theóphilo (2016) afirmam que apesar da controladoria ser manuseada por meio da junção de conceitos, ainda será baseada no padrão da contabilidade financeira. No uso de suas técnicas, a controladoria tem como o alvo fornecer para os demais braços da gestão o feedback, com o intuito de tomar decisões para melhor desenvolver o desempenho organizacional.

Segundo o estudo de Gomes (2014), pode-se afirmar que mesmo que administração, contabilidade e economia sejam importantes, bem como mesmo que atuem de maneira integrada, levando em consideração o conteúdo aqui exposto, é preciso entender que na controladoria, por exemplo, o $\mathrm{RH}$ e marketing são tão importantes quanto.

Segundo Oliveira et al. (2011), a controladoria é considerada por vários autores não apenas como uma junção entre ferramentas dos mais diversos tipos, mas, também, como um novo estágio relacionado à área da contabilidade. Com o decorrer do tempo, a contabilidade comum sofreu uma modificação, focando sua usabilidade no controle financeiro de empresas para alcançar um controle total, com acréscimo da administração, desencadeando, assim, uma atualização no setor, aprimorando a controladoria, considerada por muitos como a contabilidade atual ou contabilidade contemporânea. 


\subsubsection{ORIGEM DA CONTROLADORIA}

Segundo John e Kaplan (1987 apud SOUZA, 2015, p. 2),

Por conta da revolução francesa no século XIX, as empresas primárias e secundárias norte-americanas estavam crescendo de forma rápida, encontrando assim grande necessidade por parte de procuradores e sócios uma nova maneira de obter controle sobre o crescimento das organizações.

Foi durante esse período que a controladoria se deu início. De acordo com Tung (1997 apud SOUZA, 2015, p. 2)

A controladoria veio para difundir e aumentar o modus operandi organizacional apontando quais elementos estão acrescentando ou não para a efetividade dos procedimentos de maneira que o negócio tenha segurança econômica futura.

$\mathrm{Na}$ década de 60, o país estava vivenciando uma terrível instabilidade econômica e sofrendo mudanças profundas no governo. O presidente, até então, era Juscelino Kubitscheck e, durante seu mandato, abriu as portas para a chegada de indústrias do exterior. Por conta da chegada dessas empresas, a concorrência cresceu imensamente, logo, a saída das empresas locais implicou a necessidade de aprimorar o conhecimento sobre manufatura e organização gerencial. Foi durante esse processo que a controladoria se tornou conhecida no Brasil. Segundo Ribeiro (2010), durante o governo de Juscelino K, a manufatura cresceu em torno de $20,4 \%$ em relação ao total do planejamento imaginado.

\subsubsection{DEPARTAMENTOS DE CONTROLADORIA}

Dentro do contexto de controle interno, a controladoria, pode ter como objeto as esferas adequadas a serem implantadas na organização gerencial. Alguns aparatos relacionados à controladoria contábil fiscal podem ser listados, sendo influentes no planejamento.

Segundo Fia (2020), uma adversidade enfrentada pelas empresas, acrescenta mais alguns modelos que podem ser aplicados à lista, tendo, como base, as

RC: 100632

Link de acesso:

https://www.nucleodoconhecimento.com.br/administracao/ferramenta-organizacional 
particularidades de cada empresa. A controladoria, como ferramenta organizacional, abrange algumas formas de controle perante as empresas, sendo elas controladoria contábil e fiscal. A controladoria fiscal e contábil atua como a junção de vários serviços de suporte. De acordo com Nakagawa (1994 apud SOUZA, 2015, p. 44), a controladoria como função refere-se a uma juntura que tem um propósito comum.

A partir do exposto, menciona-se que a juntura é composta pelas compras, relatórios, finanças etc. Segundo Anthony e Govindarajan (2008 apud MORAIS; OLIVEIRA, 2016), o controle gerencial obtém-se a partir de um agrupamento de atribuições que foram concebidas para garantir que os projetos sejam concluídos, precisando-se, assim, de um sistema para ser criado. O modelo de gestão é aplicado conforme a necessidade das variadas empresas existentes. De acordo com Nascimento (2013), o foco dos modelos, como os de decisão, informação e mensuração, é fazer com que tudo seja realizado de acordo com os valores dos gestores, sendo favorável à organização.

\subsubsection{FUNÇÕES DA CONTROLADORIA}

A controladoria possui variadas funções, dentre as quais Kanitz et al. (1977 apud GOMES 2014, p. 14) destacam como principais as funções chamadas: informação, motivação, coordenação, avaliação, planejamento e acompanhamento.

1. Informação: agrupamento da contabilidade e financeiro da empresa que estão presentes durante o começo e fim do processo;

2. Motivação: providenciada de acordo com resultado da aplicação comportamental;

3. Coordenação: concentração das demandas informativas visando à vigilância e recomendação das dissoluções;

4. Avaliação: esclarecimentos e formação de parecer;

5. Planejamento: segmentação e averiguação dos procedimentos e aprovação para futuras utilizações; 
6. Acompanhamento: comitiva que tem como objetivo a reparação dos efeitos do plano

Já do ponto de vista de Heckert e Wilson (1997 apud FIIRST et al., 2018, p. 4) as funções da controladoria são:

1. Planejamento: realizado por meio da revisão de um projeto, com tempo extenso ou reduzido;

2. Controle: acontece no decorrer do prosseguimento, a partir de meios pertinentes, com base nos exemplos corretos;

3. Relatar: inclui a preparação da averiguação dos dados financeiros por relatórios;

4. Contábil: administrar a empresa como um todo, contando-se com a coleta de informações reunidas dos livros contábeis para registros e adequações deles;

5. E demais funções como: obrigações de fonte local, federal ou estadual, relações com fisco etc.

As funções da controladoria têm como objetivo dirigir os interesses visando o sucesso na produção. Segundo Tung (1974 apud SILVA, 2018, p. 6), as funções existem para que a aplicação do recurso seja cumprida, segundo matriz empresarial.

\subsection{CONTROLLER}

A palavra controller se refere ao profissional que aplica a controladoria com a finalidade de controlar e averiguar todos os procedimentos organizacionais, além de conceituar o comportamento das tarefas depois de concretizadas. Certamente, o controller não usa como ferramenta somente a contabilidade, porém, há uma gama de propriedades que permitem o gerenciamento da demanda empresarial, como controle, planejamento etc.

Conforme Meirelles Júnior (2009), o profissional que aplica a controladoria deve estar sempre equipado de conhecimentos para determinados fins, como: estatística, contabilidade, economia etc. O papel do controller é realizar as tarefas nas

RC: 100632

Link de acesso:

https://www.nucleodoconhecimento.com.br/administracao/ferramenta-organizacional 
organizações da melhor forma possível. De acordo com lpog (2018), as responsabilidades do controller podem ser:

1. Planejamento, organização e desenvolvimento dos planos;

2. Averiguação da contabilidade para que se obtenha mais ganhos e menos perdas, logo, há o aumento de faturamento empresarial;

3. Definição do alinhamento referente à elaboração econômica estratégica da instituição;

4. Verificação concernente ao local onde a organização está situada;

5. Examinar as fases operantes;

6. Apresentar prováveis melhorias e estabelecer correções

\subsection{MICRO E PEQUENAS EMPRESAS}

Em conformidade com Lemes Júnior e Pisa (2010):

Tendo em vista a perspectiva das importâncias das micro e pequenas empresas perante o racionamento financeiro do país, é correto afirmar o explícito crescimento das empresas de pequeno porte perante o meio onde está inserida, pois é notável a relevância do seu papel no desenvolvimento da economia no gerenciamento de empregos, divisão de lucro e formação de montante.

De acordo com dados do Anuário do Trabalho da MPES (2006):

Existem em média 16,2 milhões de micro e pequenas empresas, dentre elas, 5,9 milhões de empresas formais e 10,3 milhões informais; 28 milhões de postos de trabalho (sendo $67 \%$ do total de trabalhos formais e informais); já no setor formal urbano são $51 \%$ dessas empresas são privados e incluem cerca de 13,2 milhões de postos de trabalho; $85 \%$ das empresas rurais são familiares que é o que vale a 4,1 milhões desse valor; $38 \%$ de massa salarial; $28 \%$ de receita bruta; $20 \%$ PIB; $13 \%$ fornecimento para o governo; e $2,7 \%$ equivalem às exportações.

Devido a diversidade de medições para definir o que são as micro e pequenas empresas, não há somente uma fórmula para significação. De acordo com Lemes Júnior e Pisa (2010a) 
Não existe critério certo para a definição de micro e pequenas empresas, nem nos outros países nem no Brasil, isso porque existem várias formas de especificação, tanto no país quanto no exterior, entre as instituições particulares ou de suporte.

A classificação pode ser feita a partir dos contribuintes empresários, quando estes prestam dados quanto ao faturamento (receita bruta obtida com as vendas ou prestação de serviço, no exercício tributário). Isso ocorre porque os significados são diferentes, usando-se, então, o propósito em comum, que é o enquadramento das empresas. Por exemplo, o BNDS opera pela receita bruta, de acordo com a Lei do Simples Nacional; já o Sebrae opera a partir da quantidade de empregados. Apresentando o que são micro e pequenas empresas tendo como hábito comum os seus fechamentos Rocha (2008 apud BALDISSERA, 2010, p. 28) evidencia que:

Que alguns fatores para a designação das micro e pequenas empresas no Brasil, são necessárias que algumas ponderações sejam aplicadas junto a economia. As MEPS não são abreviações de empresas, nem são gerenciadas por subdivisão ou por parcelas. Habitualmente tem sua demanda marcada mais fortemente no segmento serviços, bens e produtos com aspecto dobradiço e com extensas mudanças com o tempo; não se encontram dificuldades para sua entrada perante o mercado principalmente por conta da disputa entre eles, porém apresenta como obstáculo sua permanência perante o comércio, adquirindo o sumiço a partir de dois anos.

Moraes (2006 apud BALDISSERA, 2010, p. 23) frisa que:

Que para preservarmos êxito nesta demanda, as micro e pequenas empresas precisam aprimorar sua gerência institucional. É nesse momento que percebemos a necessidade de uma pessoa qualificada na região da contabilidade, que poderá ser suporte para a gestão que busca entendimento dos processos que são envolvidos nas organizações.

Tendo em vista todo o conhecimento sobre a origem, importância e a classificação das MEPS, é correto afirmar que para sua permanência, e não destituições por conta de falta de gestão, é preciso estabelecer bases sólidas. De acordo com Rocha (2018), a conquista das micro e pequenas empresas provém, principalmente, de três categorias, sendo elas: processos, indivíduos e as mercadorias.

RC: 100632

Link de acesso: 


\subsubsection{INFLUÊNCIA DA CONTROLADORIA NA GESTÃO DAS MICRO E PEQUENAS EMPRESAS}

Para Oliveira (2010), pode ser considerado como uma ferramenta o procedimento que possui o objetivo de alcançar um dado contexto em um futuro desejado por meio de competência e efetividade, convergindo com diligências e artifícios. A busca por estratégias coerentes é que fará com que a efetividade seja alcançada. De acordo com Padoveze e Taranto (2009), é a partir dos instrumentos ligados à controladoria que os processos se tornam mais eficazes, pois adquire-se soluções para problemas gerenciais, diminuindo, assim, a quantidade de falências empresariais. A controladoria pode ser usada com o intuito de evitar a dissolução das MEPS, tendo em vista, de acordo com estudos que, poucas conseguem se manter após dois anos de atividade.

Segundo uma pesquisa que contou com quarenta pequenas empresas, Wahlmann (2003 apud CARNEIRO NETO, 2018), notou que apesar de gestores possuírem formação acadêmica, há incompreensão quanto ao manuseio de custos, inexistência do gerenciamento, privação de estratégias, iniciativas e acomodação quanto à busca por conhecimento. Compreendemos, então, que o uso da controladoria nas micro e pequenas empresas têm grande valor, pois são ferramentas auxiliadoras. Segundo Nascimento e Reginaldo (2007 apud CARNEIRO NETO, 2018), a controladoria, por meio de suas metodologias, toma forma a partir de um padrão de atos ordenados, autorizando a averiguação do andamento, oferecendo suporte para a sentença final, colaborando com o êxito das atividades.

\subsection{PRINCIPAIS FERRAMENTAS DA CONTROLADORIA PARA GESTÃO}

De acordo com Martins (2005 apud VALVERDE et al., 2018, p. 4):

A controladoria tem como objetivo oferecer informações corretas para o processo de tomada de decisão dos organizadores, contribuindo para a procura do êxito das empresas em suas subdivisões. Se tornando assim

RC: 100632

Link de acesso:

https://www.nucleodoconhecimento.com.br/administracao/ferramenta-organizacional 
dispositivo de máxima importância e relevância para a constância organizacional da empresa.

Segundo Horngren (1971 apud VALVERDE et al., 2018, p. 4):

As ferramentas da controladoria podem ser: a) organização para o comando; b) Circulares e observações; c) Parecer e assistência; d) Controle dos tributos; e) Descrições para o governo; f) Defesa dos ativos; g) Parecer econômico.

Já para Padoveze (2012), a responsabilidade da controladoria perante a rede de referências gerenciais equivale à coordenação das atividades por meio do recurso de supervisão, usado pelos gestores para garantir a coerência no sistema de dados contábeis.

\subsubsection{BALANCED SCORECARD}

Conhecido como BSC, o Balanced Scorecard, participa da contabilidade como um modelo que fornece elementos gerenciais. De acordo com Frezatti (2009), o objetivo do BSC é:

[...] determinar um relacionamento entre a efetividade e os procedimentos através do posicionamento entre tática de negócios e a atuação funcional, empregando formação equilibrada de medidas, alvos e condições para devidos propósitos.

Segundo Frezatti (2009), o BSC intervém diretamente nas tomadas de decisões dos administradores e gestores, o que faz com que se obtenham o controle dosnegócios, para, assim, auxiliarem no crescimento e aumento da concorrência perante as demais empresas.

Conforme o ponto de vista de Kaplan e Norton (1997 apud LIMA, 2019), o Balanced Scorecard expõe, em sua composição, quatro aspectos que conduzem os processos de tomadas de decisões. As quatro são: financeira, clientes, processos internos e crescimento e aprendizado.

RC: 100632

Link de acesso: 


\title{
2.4.1.1 PERSPECTIVA FINANCEIRA
}

A dimensão financeira para Kaplan e Norton (1997 apud CAMPOS; FALKOWISKI, 2014) é:

\begin{abstract}
Qualquer quantia separada deve ser elemento de uma corrente de relações entre fator e resultado que findam com avanços no funcionamento financeiro da gestão. A história deve ser contada de acordo com o BSC possuindo elementos estratégicos, tendo início nos processos financeiros de longo prazo correlacionando-se com processos financeiros dos clientes internos, juntamente com processos dos funcionários, a fim de ser produtivo o desempenho, alcançando o objetivo econômico esperado.
\end{abstract}

A possibilidade de enxergar-se as ligações entre as extensões é proporcionada por conta da ligação adquirida pelo BSC. É devido a esses processos que se obtém a agregação dos valores que colaboram com a alteração e aquisição de novos clientes. Segundo Campos e Falkowiski (2014), o estabelecimento do âmbito econômico e financeiro firmes no comércio, são resultados conquistados por meio de indicativos convincentes, localizados a médio e longo prazo.

De acordo com Muller (2014), os propósitos financeiros servem para orientação a longo prazo, como, também, aplicam-se às metas com fins táticos. Em concordância, Fernandes e Berton (2005 apud WANDERLEY, 2018) acreditam que a concepção financeira lida com tópicos da gestão, com o foco na verificação, nas escolhas das estratégias e verifica-se se as mesmas estão adicionando algo à criação e aumento de renda da empresa. Segundo Lobato (2009), a geração e aplicação das técnicas podem colaborar para o crescimento financeiro a partir das proporções e metas financeiras.

\subsubsection{PERSPECTIVAS DE CLIENTES}

Conforme Campos e Falkowiski (2014), antes de usar o BSC, ferramenta de apoio, a decisão do segmento do mercado deve ser tomada, tornando consolidado o valor. Feita a escolha da segmentação a ser usada, o BSC pode ser empregado como suporte para a criação da atribuição de valores pelos clientes. A composição da 
proporção do cliente pode ser vista a partir dos valores da tributação aplicado às mercadorias e serviços, contudo, esses valores devem estar ligados aos indicativos de resultado, com foco na perspectiva dos clientes.

Conforme Frezatti (2009), os clientes têm sua perspectiva estruturada em alguns pontos, tais como: atuação no mercado; conservação; compreensão; contentamento; e lucro.

De acordo com Herrero Filho (2005 apud WANDERLEY, 2018) a opinião dos clientes deve indicar qual é o valor, tem como ponto de partida a avaliação do desempenho das metas, avalia-se se as escolhas dos procedimentos têm contribuído para o crescimento da quantia e se têm coesão com os produtos, serviços e imagem da marca.

\subsubsection{PERSPECTIVAS DE PROCESSOS INTERNOS}

Conforme Maroni Neto (2001 apud WANDERLEY, 2018) as finalidades dos processos internos têm formação a partir da identificação e geração do processo e valor para o comprador a partir de sua satisfação e crescimento. O ponto de vista de Herrero Filho (2005 apud CAMPOS; FALKOWISKI, 2014) afirma que os processos e análises focam na qualidade e produção dos procedimentos para os clientes. Já Miller (2014) consente que para chegar à excelência é indispensável identificar os procedimentos analíticos.

\subsubsection{PERSPECTIVAS DE APRENDIZAGEM E CRESCIMENTO}

Sendo pressionada pelo avanço da tecnologia, as empresas precisam buscar pelo progresso a partir da capacitação em liderança corporativa. Cabe à regência administrativa transacionar da sustentabilidade para a contenção do entendimento. Segundo Crawford (1994 apud CAMPOS; FALKOWISKI, 2014), deve-se mencionar que a compreensão de um todo é a competência de aumentar conhecimento a um certo ponto característico. Implica aptidão em criar, definir, averiguar e determinar 
padrões, transformar referências em fundamentos. Para Campos e Falkowiski (2014), o componente humano é o intermediário decisório ao êxito nas empresas. Por incumbência, necessita-se de um cuidado maior nas áreas de $\mathrm{RH}$ e progresso do capital humano.

\subsubsection{ESTRATÉGIAS DE CUSTOS}

De acordo com Santos (2017), o sistema de contas da contabilidade de custos é formado por regulamentos e princípios para a amontoação, constituição e estudo de dados, sendo que o sistema auxilia nas demandas internas e externas da entidade. Conforme Martins e Theóphilo (2016), até a revolução industrial no século XVIII, apenas era conhecida a contabilidade financeira, voltada à área mercantilista. $O$ contador verificava a quantia paga por elemento estocado. Dessa maneira, reconhecia as mercadorias. Portanto, as mudanças ocorreram quando a contabilidade financeira já não era mais suficiente para contestar perguntas relacionadas ao custo. De acordo com Frezatti; Aguiar e Guerreiro (2007 apud SANTOS, 2017):

A contabilidade financeira já não era o suficiente para lidar com os processamentos dos gastos, por meio da revolução industrial foi constatado insuficiência. O ponto em questão era não somente a comercialização de mercadoria, mas a modificação da matéria prima, adicionando pertences dando origem a novos objetos e serviços que careciam de reaproveitamento, dando surgimento à controladoria de custos.

\subsubsection{DESPESA X CUSTO}

De acordo com Hendriksen e Breda (2001 apud SANTOS et al., 2012), a medição do valor presente nos meios de contenção utilizados ou a serem utilizados são anexados no conseguimento de capital e serviços, traduzindo, refere-se ao valor de troca. Logo, os lucros não alteram o processo de obtenção. No ponto de vista de Santos et al. (2012), as despesas são definidas quando diminuem os lucros, ou seja, demonstra-se a ação do consumo de bens e serviços no procedimento de aquisição de receitas. Em resumo, segundo Santos et al. (2012), a despesa, em geral, é 
presumível e avaliada em um determinado tempo e não conforme o mercado ou processo do mercado.

Custo, entretanto, no significado da palavra, retrata um martírio de recursos relacionados à criação de bens e serviços, consequentemente, não altera o patrimônio líquido da entidade.

\subsubsection{CLASSIFICAÇÃO}

É contido no custo de produção e classifica-se como custo direto e custo indireto. Normalmente, estão ligados, diretamente ou indiretamente, à matéria-prima, embalagem, salários, aluguéis, depreciação de máquinas.

\subsubsection{CUSTOS DIRETOS}

De acordo com Santos (2018), entende-se que custo direto é aquele que pode ser facilmente identificado, devido ao objeto de custo constar nos vetores finais, quando visto singularmente.

\subsubsection{CUSTOS INDIRETOS}

Em contradição ao custo direto, de acordo com Santos (2018), custo indireto é quando a assimilação é feita indiretamente por meio de padrões já determinados, consequentemente, não é calculado nos vetores finais.

Em conformidade com Martins e Theóphilo (2016), entende-se que a especificação de custo direto e indireto como uma mercadoria feita ou como serviço prestado, e não como a formação como um todo.

\subsubsection{CUSTO FIXO}

De acordo com Koliver (2002 apud SANTOS, 2018), custos fixos são aqueles que tem tendência a manter-se em certas divisas no uso da aptidão de produção. Os 
custos fixos continuam interruptos, independentemente das alterações na operação, observando sempre a habilidade situada.

\subsubsection{CUSTO VARIÁVEL}

Conforme Santos (2018), os custos variáveis alteram as elevações das atividades, itens produzidos ou vendidos. Em preparação, esta classificação possibilita aos gestores antever o que poderá acontecer em sua organização em termos de custos, encargos e alterações nos graus das atividades.

\subsubsection{FORMAÇÃO DE PREÇO DE VENDA}

O planejamento do preço de venda é tomado, inicialmente, a partir do discernimento de custo e métodos de custeio, comparando os resultados atingidos de antemão, considerando-se os meios incluídos na comercialização. De acordo com Martins (2017), para gerenciamento dos preços de venda, é indispensável o conhecimento referente ao custo da mercadoria. A geração de preços para vendas é feita pela somatória dos custos e despesas necessárias para o desenvolvimento dos afazeres estendidos a uma margem de lucro almejado. Tais cuidados são essenciais à obtenção do êxito.

Conforme Martins (2017), a criação de base na indústria tem, como princípio, a conjectura inaugural e suposição do valor que o cliente está disposto a dar, com suporte aos preços dos produtos parecidos que serão gerados. Uma das maneiras de levantamento para a geração de valores é por meio do custo meta. O método de custo meta estabelece, a partir do valor do mercado, a despesa e margem de lucro almejado. Santos (2018), afirma que a ferramenta de custo meta, do mesmo modo, pode ser utilizada para firmar metas de rendimento, contribuindo para a diminuição de custos totais e propriedades esperadas. 


\subsubsection{ORÇAMENTOS}

Para Chagas e Araújo (2013), o orçamento empresarial é a técnica gerencial a partir da qual os interesses coletivos são agrupados e implementados, utilizando as informações contábeis como base para análise de desempenho, planejamento e execução de metas, gestão de estratégias e comparação de resultados. Pode-se entender que o orçamento é uma ferramenta de planejamento e, principalmente, controle de metas e objetivos financeiros, empregados durante um período determinado. $\mathrm{O}$ orçamento empresarial é um produto do planejamento estratégico e atua como alerta aos gestores, indicando se o plano é eficaz. É um plano financeiro e cronológico, normalmente, para um ano, bem como visa implementar a estratégia escolhida (FREZATTI, 2009).

O orçamento empresarial, diante do aqui exposto, tem sido considerado como método original, sendo um dos mais utilizados pelas organizações. Padoveze e Taranto (2009) comentam que nele as peças orçamentárias são elaboradas a partir da fixação de volumes de vendas e, por meio deles, são determinados os volumes de atividades e setores da empresa. A elaboração do orçamento empresarial ocorre somente uma vez a cada exercício, ou seja, no exercício corrente são realizadas as previsões para o exercício subsequente. Carneiro e Matias (2011) destacam que, dentre as características fundamentais do orçamento empresarial, está a não permissão de alterações nos orçamentos departamentais (de receitas e de gastos).

\subsection{GESTÃO DE MICROEMPREENDEDORES}

Historicamente, o conceito de empreendedor passou a ser empregado em meados do século XVII por alguns especialistas. De acordo com Paulo Ferreira (2015), o primeiro a utilizar o termo no cenário organizacional foi o empresário francês Richard Cantillon. De acordo com Drucker (2002 apud BARBOSA; COSTA, 2015, p. 12) um dominante significativo é o aproveitamento que os empresários usam para criar mudanças, levando em consideração que esse traço seja um comportamento e não um caráter.

RC: 100632

Link de acesso:

https://www.nucleodoconhecimento.com.br/administracao/ferramenta-organizacional 
Fora as diversas qualidades e definições que um empreendedor precisa ter, de acordo com Dornelas (2012), o empresário precisa possuir particularidades de empreendedor, como a soma de características sociais e ambientais, o que consente com uma concepção quanto ao surgimento de modificações empresariais. Possuir características de um empreendedor não é sinônimo de sucesso. A partir dessa conclusão, o gestor precisa caminhar em busca de conhecimento para melhorias. Segundo Santos et al. (2012):

No início de sua jornada perante o mercado, o empreendedor além de procurar o bem exato, precisa estar em busca de modernização para atender as necessidades da demanda e concorrência.

Dentre as causas relacionadas à decadência empresarial, esta a falta de controle interno. Conforme Melo (2010), existem alguns erros básicos que, quando executados, colaboram para o enfraquecimento da empresa, como: contratar pessoas desqualificadas para o cargo; tomar medidas sem consultar informações financeiras; e confundir as finanças pessoais com as da empresa. Em empresas como as MPE, o empresário atua, também, como gerente, administrador. De acordo com Lemes Júnior e Pisa (2010b), o cargo gestor envolve, em especial, a influência e interlocução. Usando os procedimentos de forma correta e entendendo o processo da empresa, será, assim, capaz de utilizar as estratégias de seus colaboradores, encaminhando-os para certos setores com finalidade de sistematizar sua performance.

\section{MATERIAIS E MÉTODOS}

Caracteriza-se a metodologia como uma junção de várias ferramentas formadas por determinadas regras com o objetivo de entender o conhecimento e verificar dados, sendo um processo fundamental que examina a veracidade das informações durante a sua articulação.

RC: 100632

Link de acesso:

https://www.nucleodoconhecimento.com.br/administracao/ferramenta-organizacional 


\subsection{PROCEDIMENTOS METODOLÓGICOS}

Segundo Almeida (2017), observou-se que o método científico é um mecanismo utilizado para aprovação e definição de uma tese por meio da junção de informações. Desta forma, este artigo elaborou-se a partir da junção de vários instrumentos, como recolhimento e manuseio dos dados, juntamente com suas referências, sendo essas fundamentadas e devidamente organizadas para melhor expressarem a certificação e compreensão do conteúdo durante o desenvolvimento do assunto para os leigos.

\subsubsection{QUANTO À NATUREZA}

De acordo com Flick (2009), confirmou-se que os pesquisadores de várias áreas evidenciam que o uso de pesquisas quali-quantitativas tem aumentado consideravelmente nos últimos anos. Conforme Flick (2009):

Observou-se que as relações entre qualitativo e quantitativo tem como objetivo oferecer uma interpretação completa do objeto em questão. Indo por essa linha de raciocínio tanto o método qualitativo quanto o quantitativo podem se apoiar, proporcionando diagnóstico usando os dois métodos.

O método empregado no estudo científico justifica-se pois necessitou-se, não somente de pesquisas baseadas em estudos de origem social, mas também de estatísticas para sua construção principal, colaborando, de igual modo, com os métodos quantitativos e qualitativos. Adquiriu-se como finalidade a produção de conhecimento e de possível aplicação em estudos.

\subsubsection{QUANTO AOS FINS}

De acordo com Andrade (2012), a motivação da pesquisa aplicada surge como uma necessidade a ser cumprida perante a atualidade contemporânea e teve como objetivo colaborar com a aplicação de métodos para resolução de objeções. Em concordância com Gil (2019), mesmo que a pesquisa básica possua finalidade distinta à da pesquisa aplicada, pode contribuir com a dissolução de problemas, 
assim como a aplicada, ambas podem auxiliar no desenvolvimento de novos conhecimentos. Quanto aos fins, indicou-se como ferramenta a pesquisa aplicada e mesmo que o objetivo seja apresentar as informações a partir do conhecimento, contribui, também, com a dissolução de possíveis mudanças.

\subsubsection{QUANTO AOS MEIOS}

Descreve-se que o conceito de pesquisa bibliográfica provém do conglomerado de materiais, fruto de estudos de todos os tipos como pesquisas, como artigos e livros, cujo intuito é o de responder às perguntas derivadas de problemas ou dúvidas. Conforme Martins e Theóphilo (2016), é indispensável enquanto utensílio à aprendizagem da edificação do cenário de aprendizado. De acordo com Gil (2017), a estrutura das pesquisas bibliográficas se dá por meio de conteúdos já publicados. Quanto aos meios, coletaram-se dados por meio da pesquisa bibliográfica, que é gerada a partir de material divulgado como suporte de estudo científico, oriundo de anos de história, contado a partir das variedades de listas de livros.

\section{CONSIDERAÇÕES FINAIS}

O objetivo determinante desta pesquisa foi mostrar a aplicação da controladoria nas organizações de micro e pequenas empresas e, consequentemente, fazer com que elas permaneçam mais tempo, gerando empregos e melhorando a economia do país. De acordo com o previsto na tese, foi explanado, no decorrer da pesquisa, o conceito de controladoria, a época que começou a ser empregada no mundo e no Brasil, bem como foi exposta a primazia de sua importância por meio da explanação das funções e dos benefícios agregados às organizações empresariais de diversas naturezas na atualidade. Em resposta à questão da pesquisa: quais as ferramentas que a controladoria pode proporcionar para gestão das micro e pequenas empresas? Foi possível observar, ao longo da pesquisa, o ambiente interno e externo organizacional e, concluímos que a controladoria pode proporcionar ferramentas a partir do balanced scorecard, estratégias de custos e orçamentos. 
Estas ferramentas podem ser aplicadas à gestão das microempresas, pois fomentam resultados positivos.

Por conta de as microempresas possuírem uma alta taxa de mortalidade com até dois anos de atividade, a pesquisa procurou fornecer subsídios quanto a esta questão. Uma das soluções encontradas diz respeito à profissionalização do gestor, sendo que este, recorrentemente, é o empresário do empreendimento, melhorando, assim, a saúde da empresa, evitando o fechamento.

Propõe-se a realização de estudos futuros com finalidade de acrescentar à demonstração do conteúdo aqui mencionado. Posteriores informações podem ser argumentadas em desígnio de interesse público ou do contador. Neste contexto, a relevância das referências ao tema controladoria se dá devido à expansão do debate sobre possibilidades atuais.

\section{REFERÊNCIAS}

BALDISSERA, B. M. Estudo sobre a utilização das informações contábeis nas microempresas e empresas de pequeno porte. 2010. 59f. TCC (Bacharel em Ciências Contábeis) - Universidade Federal de Santa Catarina, Florianópolis, SC, 2010.

BARBOSA; COSTA. Perfil empreendedor. 2015. 48f. TCC (Bacharel em Administração) - Universidade Federal Fluminense, Volta Redonda, RJ, 2015.

BASTOS. Gestão de custos: análise aplicada a uma microempresa franqueada de sorvetes em João Monlevade. 2018. 48f. TCC (Bacharel em Engenharia de produção) - Universidade Federal de Ouro Preto, João Monlevade, MG, 2018.

BERNARDO, B. Controladoria Contábil: saiba como funciona e quais os benefícios. Campinas, 16 de out. de 2019. Disponível em: https://syhus.com.br/2019/10/16/controladoria-contabil/. Acesso em: 16 out. 2019.

RC: 100632

Link de acesso: 
CAMPOS, I. de. F.; FALKOWISKI, L. Administração estratégica. Londrina: UNOPAR, 2014.

CARNEIRO NETO, J. B. Controladoria em micro e pequenas empresas. 2018. 30f. Artigo (Bacharel em Ciências Contábeis) - Universidade Federal de Uberlândia, Uberlândia, MG, 2018.

CARNEIRO, M.; MATIAS, A. B. Orçamento empresarial: teoria, prática e novas técnicas. São Paulo: Atlas, 2011.

CHAGAS, M. J. R.; ARAUJO, A. O. Orçamento Empresarial como Ferramenta de Auxílio à Gestão: Um Estudo Empírico nas Indústrias de Calçados da Cidade de Campina Grande - PB. REUNIR - Revista de Administração, Contabilidade e Sustentabilidade, n. 3. v. 3, p. 1-21, 2013

COSTA, E. da. S. Formação do preço de venda e estratégias de precificação: estudo de caso na açofer comércio de ferragens Itda da cidade de Gurupi - TO. 2018. 20f. TCC (Bacharel em Administração) - Centro Universitário UNIRG, Gurupi, TO, 2018.

DAL PICOL, P. Rádio e jovens caxienses: sinalizadores de escuta. 2019. 129f. TCC (Bacharel Comunicação social), Universidade de Caxias do Sul, Caxias do Sul, RS, 2019.

DORNELAS, J. Empreendedorismo: transformando ideias em negócios. $4^{\text {a }}$ Edição. Rio de Janeiro: Elsevier, 2012.

FERNANDES, A. M.; GALVÃO, P. R. A Controladoria como ferramenta de gestão nas micro e pequenas empresas: um estudo da viabilidade e da relação custo benefício. Revista de Tecnologia Aplicada, v. 5, n. 1, 2016.

FERREIRA, P. Empreendedorismo: uma abordagem sintética. $1^{1 \underline{a}}$ ed. Estrada da Penha: Sílabas \& desafios, 2015. 
FIA. Controladoria vejo o que é, seus tipos e sua função na empresa. Blog Upis Graduação e Pós-graduação, DF, 16 de dez. de 2019. Disponível em: https://upis.br/blog/controladoria/. Acesso em: 16 dez. 2019.

FIA. Controladoria: o que é, tipos e qual a função? Fundação Instituto de Administração, São Paulo, 06 de jun. de 2020. Disponível em: https://fia.com.br/blog/controladoria/. Acesso em: 06 jun. 2020.

FIIRST, C. et al. Perfil do controller e a evolução histórica da profissão no contexto brasileiro. Enfoque: Reflexão Contábil, v. 37, n. 2, p. 01-20, 2018.

FREZATTI, F. Orçamento Empresarial: Planejamento e Controle Gerencial. 5a ed. 2aㅡ reimpr. São Paulo: Atlas, 2009.

GARCIA, R. Controladoria. Londrina: UNOPAR , 2014.

GIL, A. C. Como elaborar projetos de pesquisa. 6ª ed. São Paulo. Atlas, 2017.

GOMES. A controladoria e o processo de gestão organizacional. 2014. 39f. TCC (Bacharel em Administração) - Instituto Municipal de Ensino Superior de Assis, Assis, SP, 2014.

HIDEKI ANAGUSKO MANAGEMENT CONSULTING. A controladoria aplicada às micro e pequenas empresas no Brasil. Hideki Anagusto Management Consulting, São Paulo, 2018. Disponível em: http://hidekianagusko.com.br/controladoriaaplicada-as-micro-e-pequenas-empresas-no-brasil-artigo-cientifico/. Acesso em: 18 mar. 2018.

HISRICH, R. D. et al. Empreendedorismo. 9a ed. New York: Amgh Editora Ltda, 2014.

LEAL, A. B. et al. Controladoria empresarial. Salvador: EDUFBA, 2010.

RC: 100632

Link de acesso:

https://www.nucleodoconhecimento.com.br/administracao/ferramenta-organizacional 
LEMES JÚNIOR, A. B.; PISA, B. J. Administrando micro e pequenas empresas. Rio de Janeiro: Elsevier Editora Ltda, 2010a.

LEMES JÚNIOR, A. B.; PISA, B. J. Micro e pequenas empresas. Rio de Janeiro: Elsevier Editora Ltda, 2010b.

LIMA, A. C. F. Proposta de Balanced scorecard para a instituição de ensino superior privada: estudo de caso no núcleo de educação a distância de uma faculdade. 2019. 73f. TCC (Bacharel em Engenharia de produção) - Universidade Federal do Ceará, Fortaleza, CE, 2019.

MARTINS, G. de.; THEÓPHILO, C. R. Metodologia da investigação científica para ciências sociais aplicadas. $3^{\mathrm{a}}$ ed. São Paulo: Atlas, 2016.

MARTINS, L. A. Adversidades do empreendedorismo de micro e pequenas empresas no Brasil. 2017. 35f. TCC (Bacharel em Administração de Empresas) Kroton Educacional, Anhanguera, Pirassununga, SP, 2017.

MORAIS, H. A. de.; OLIVEIRA, S. R. A. de. Controle gerencial: uma análise nas empresas contábeis da cidade de Caicó/RN. Revista UNEMAT de Contabilidade, v. 5, n. 9, 2016.

OLIVEIRA, D. P. R. Planejamento Estratégico: conceitos, metodologia e práticas. $27^{a}$ ed. São Paulo: Atlas, 2010.

OLIVEIRA, L. M. de. et al. Controladoria estratégica. $7^{\mathfrak{a}}$ ed. São Paulo. Atlas, 2011.

PADOVEZE, C. L. Contabilidade gerencial. Curitiba: IESDE Brasil S.A. 2012.

PADOVEZE, C. L. Controladoria Básica. $2^{\mathrm{a}}$ ed. São Paulo: Cengage Learning, 2010.

PADOVEZE, C. L.; TARANTO, F. C. Orçamento empresarial: novos conceitos e técnicas. São Paulo: Pearson Education do Brasil, 2009. 
PÁDUA, J. V. de.; SILVA, K. de. P. A importância do planejamento estratégico para micro e pequenas empresas. 2017. 44f. TCC (Bacharel em Administração) Faculdade Calafiori. São Sebastião do Paraíso, MG, 2017.

PAULA, G. de. Controladoria nas Empresas: Funções, Estrutura e Importância. Treasy - Planejamento e Controladoria, Joinville, 06 de maio. de 2019. Disponível em: https://www.treasy.com.br/blog/controladoria-nas-empresas/. Acesso em: 06 mai. 2019.

PEREIRA, A. S. et al. Metodologia da pesquisa científica. $1^{\underline{a}}$ ed. Santa Maria: UFSM, NTE, 2018.

ROCHA, J. S. da. Introdução à controladoria. Salvador: UFBA, Faculdade de Ciências Contábeis; Superintendência de Educação a Distância, 2018.

SANTOS, A. L. dos. S. et al. Micro e pequenas empresas: mercado de trabalho e implicação para o desenvolvimento. Rio de Janeiro: Ipea, 2012.

SANTOS, M. A. dos. Contabilidade de custo. Salvador: UFBA, Faculdade de Ciências Contábeis. Superintendência de Educação a Distância, 2018.

SANTOS, R. N. dos. Análise da percepção dos acadêmicos de graduação em enfermagem sobre pesquisas científicas. 2017. 52f. TCC (Bacharel em Enfermagem) - Faculdade de Macapá, Macapá, AP, 2017.

SCHNEIDER, E. M.; FUJII, R. A. X.; CORAZZA, M. J. Pesquisas quali-quantitativas: contribuições para a pesquisa em ensino de ciências. Revista Pesquisa Qualitativa, v. 5, n. 9, p. 569-584, 2017.

SEBRAE. Pequenos negócios respondem por $82 \%$ das novas vagas nos últimos meses. $2021 . \quad$ Disponível em: https://www.sebrae.com.br/sites/PortalSebrae/ufs/sc/noticias/pequenos-negociosrespondem-por-82-das-novas-vagas-nos-ultimos- 
meses,caaa6ddceeca6610VgnVCM1000004c00210aRCRD?codTema=2\&origem=te ma. Acesso em: 5 de set. 2021.

SILVA, V. B. da. As funções da controladoria: uma pesquisa nas indústrias do setor metal mecânico do estado do Rio Grande do Sul. Revista de Contabilidade Dom Alberto, v. 3, n. 6, p.107-131, 2014.

SILVA. Gestão estratégica de custos: target costing aplicado à atividade agropecuária - um estudo bibliométrico nos anais do congresso brasileiro de custos. 2018. 55f. TCC (Bacharel em Ciências Contábeis) - Universidade Estadual do Sudoeste da Bahia, Vitória da Conquista, BA, 2018.

SIMÕES. A gestão de custos como uma ferramenta estratégica nas empresas de vestuário de formiga - MG. 2016. 32f. TCC (Bacharel em Administração) Instituto Federal, Campus Formiga, Formiga, MG, 2016.

SOARES, S. V.; PICOLLI, I. R. A.; CASAGRANDE, J. L. Pesquisa bibliográfica, pesquisa bibliométrica, artigo de revisão e ensaio teórico em administração e contabilidade. Administração: ensino e pesquisa, v. 19, n. 2, p. 308-339, 2018.

SOUZA, C. G. A. de. A controladoria como ferramenta de gestão estratégica e organizacional. 2015. Monografia (Pós-Graduação) - Universidade Candido Mendes, Rio de Janeiro, RJ, 2015.

SOUZA, E. de. et al. Desafios da gestão em micro e pequenas empresas familiares na cidade de Ponta Porã-MS. In: Encontro Científico de Administração, Economia e Contabilidade, 2013.

VALVERDE, K. F. S. et al. Ferramentas da controladoria aplicadas na gestão e tomada de decisão em uma empresa distribuidora de energia elétrica. In: Congresso Brasileiro de Custos-ABC, 2018. 
VASCONCELOS, E. Controladoria para pequenas empresas: tire suas dúvidas sobre o assunto. Rede jornal contábil, Araguari, 09 de fev. de 2021. Disponível em: https://www.jornalcontabil.com.br/controladoria-para-pequenas-empresas-tire-suasduvidas-sobre-o-assunto/. Acesso em: 09 fev. 2021.

WANDERLEY, N. M. M. Um estudo sobre o processo de implantação do Balanced Scorecard. 2016. 54f. TCC (Tecnólogo em Processos Gerenciais) Instituto Federal de São Paulo, Campus Caraguatatuba, Caraguatatuba, SP, 2016.

Enviado: Outubro, 2021.

Aprovado: Novembro, 2021. 